\title{
Prevalence and Antimicrobial Susceptibility Pattern of Aerobic Bacteria Isolated from Patients with Bedsores Admitted to Intensive Care Units in Khartoum State
}

\author{
Alzpair I. Ibrahim*, Alsafi B. Mukhtar, Mahmoud H. Ahmed, \\ Suliman M. Yahia and Alamin M. Ibrahim \\ Department of Microbiology, Faculty of Medical Laboratory Sciences, \\ University of Khartoum, Sudan \\ *Corresponding author
}

\section{A B S T R A C T}

\section{Keywords}

Bedsores, Intensive Care units, Pseudomonas aeruginosa, Pressure ulcer, Acinetobacter baumannii

Article Info

Accepted: 20 April 2021 Available Online: 10 May 2021
Bedsores remain a significant healthcare concern, it is one of the most dominant problems reported by patients with mobility limitations, sometimes, it can even be life threatening, its treatment imposes financial burdens on patient's family and society. The aim of this study was to determine prevalence and antimicrobial susceptibility pattern of aerobic bacteria that causes the bedsores infection in Sudanese patients. Methods: A total of 57 bedsores swabs specimens were collected from patients with bedsores infection due to prolonged bed lying in ICUs from various hospitals in Khartoum State during the period from December 2019 to February 2020. Isolation and identification of culture isolates was done using standard bacteriological techniques and antimicrobial susceptibility testing was performed using Kirby- Bauer disk diffusion method according to Clinical and Laboratory Standards Institute guidelines. Out of 57 patients enrolled in the study, the prevalence of bedsores in ICUs patients was 50/57 (87.7\%) Both Gram positive cocci and Gram negative bacilli were isolated from 50 patients out of 57 patients. Among the Gram negative isolates, Pseudomonas aeruginosa had the highest frequency 15/41 (36.5\%), followed by Klebsiella spp 12/41 (29.2\%) and Escherichia coli 4/41 (9.7\%). The frequencies of Citrobacter freundii, Proteus spp and Salmonella spp, Acinetobacter baumannii were 3/41 $(7.3 \%)$ and $2 / 41(4.8 \%)$ respectively. The only gram positive cocci isolated was Staphylococcus aureus. The distribution of bedsores among the ages of the ICUs patients showed that age group within the range of 66-80 years recorded the highest incidence of bedsore infection. The most common site of bedsores was sacral region 36/50 (72\%) followed by neck 5/50 (10\%). All isolated Staphylococcus aureus showed 100\% resistance to Penicillin and Oxacillin but showed variable susceptibility to other antibacterial used. Pseudomonas aeruginosa was resistant to Co-trimoxazole 13/15 (86.7\%), Ciprofloxacin, and Ceftazidime 12/15 (80\%). The results showed that all isolated bacteria considered multi-drug resistance organism (MDROs) except few strains of Pseudomonas aeruginosa 2/15 (13.3\%) and Citrobacter freundii 1/3 (33.3\%). The overall prevalence of bedsores in this study was relatively high with Pseudomonas aeruginosa as the major causative agents. Multi-drug resistance of 50/53 (94.3\%) was observed among the isolated bacteria. 


\section{Introduction}

Bedsores defined as a painful often reddened area of degenerating ulcerated skin caused by pressure and lack of movement, and worsened by exposure to urine or other irritating substance on skin (Yarkony, 1994). Bedsores also known as pressure ulcer or decubitus ulcer. It is one of the most dominant problems reported by patients with mobility limitation, sometimes it can even be life threatening and its treatment imposes financial burdens on patients family and society (Repić et al., 2014; Agrawal et al., 2012). Moreover bedsores have been described as one the most costly and physically debilitating complication in the 20th century and represent the third most expensive disorder after cancer and cardiovascular diseases (Burdette-Taylor et al., 2002). The microorganisms like Enterobacteriaceae (Escherichia coli and Klebsiella pneumoniae) and non-fermenting GNB mainly Pseudomonas aeruginosa and Staphylococcus aureus are frequently associated with bedsores infection and some of this isolated bacteria exhibit multi resistant to different antibiotics including; Pseudomonas aeruginosa, Proteus spp, Klebsiella spp, Methicillin resistant Staphylococcus aureus (MRSA), Acinetobacter spp, Escherichia coli and Enterobacter spp (Braga et al., 2017). The World Health Organization (WHO) uses the incidence and prevalence of pressure ulcers as an indicator of the quality of patient care services and treatment principles (Ghodela $e t$ al., 2018).A good prevention and treatment is obligatory to avoid bedsores that can easily infect and lead to more morbidity. Curative dressings can help wound healing and avoid further problems (Chhugani et al., 2017). All pus related infections including bed sore are tricky to manage now a days due to multi-drug resistant (MDRs) bacteria (due to widespread use of prophylactic and empiric antibiotics), increased severity of illness and greater numbers of immune-compromised patients undergoing surgical procedures (Sarin et al., 2013). The main purpose of the present study was to assess the prevalence of aerobic bacteria isolated from bedsores infection from patients admitted to intensive care unit in Khartoum state and determine their antimicrobial susceptibility patterns.

\section{Materials and Methods}

Descriptive Cross sectional study was conducted from December 2019 to February 2020. Fifty seven bedsores swabs specimens were collected from patients admitted to intensive care unit at Soba University Hospital, Royal care International Hospital, Military Hospital and Omdurman Teaching Hospital. All swabs specimens were inoculated under aseptic technique in 5\% Blood agar, MacConkey agar and Mannitol salt agar prepared according to manufacturer's instruction. The inoculated culture media were incubated aerobically at $37 \mathrm{C}^{\circ}$ overnight. Gram staining was carried out initially to study morphological characteristics of clinical isolates, all Gram positive cooci identified by standard bacteriological test including; catalase test, DNAse test, coagulase test and Novobiocin sensitivity test was done to identify Staphylococcus spp. Gram negative bacilli isolates were identified by standard conventional biochemical tests including; motility test, oxidase test, Kligler iron agar, Citrate utilization test, Urease hydrolysis test, Methyl Red test and Indole production test. Antimicrobial susceptibility test for all isolates was performed by Kirby-Bauer disc diffusion method using Muller Hinton agar according to clinical laboratory standards institute (CLSI) guideline using Muller-Hinton agar (MH) (CLSI, 2015). The antibiotics discs (oxoid limited, England) used in this study were Amoxicillin $(10 \mu \mathrm{g})$, Chloramphenicol $(30 \mu \mathrm{g})$, Tetracycline $(30 \mu \mathrm{g})$, Ceftazidime $(30 \mu \mathrm{g})$,

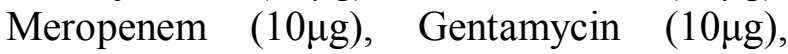


Ciprofloxacin $(5 \mu \mathrm{g})$, Vancomycin $(30 \mu \mathrm{g})$, Erythromycin $(15 \mu \mathrm{g})$, Oxacillin $(1 \mu \mathrm{g})$, Cotrimoxazole $(15 \mu \mathrm{g}), \quad$ Doxacillin $(10 \mu \mathrm{g})$ Penicillin $(10 \mu \mathrm{g})$. Staphylococcus aureus ATCC 25923 strain was used as control organism for gram positive cocci and Escherichia coli ATCC 25922 strain for gram negative bacilli respectively. Organisms that showed resistance to multiple types, classes or subclasses of antimicrobial agents were considered as multi-drugs resistant (Magiorakos et al., 2012).

\section{Statistical analysis}

Data were statistically analysed using Statistical Packaged for Social Science (SPSS) software version 20, frequency and percentages were calculated for categorical and ordinal variables. Chi- square test was performed and p-value less than 0.05 considered statically significant.

\section{Results and Discussion}

In the present study total number of 53 clinical microorganism were isolated from 57 bedsores swabs collected from Soba University Hospital, Royal care International Hospital, Military Hospital and Omdurman Teaching Hospital during the period from December 2019 to February 2020. Out of 57 swab specimens examined 50/57 (87.7\%) were positive for bacterial growth consist of $47 / 50(94 \%)$ swabs with pure bacterial isolates and $3 / 50(6 \%)$ swabs with mixed pathogens and $7 / 57(12.3 \%)$ swabs were negative for bacterial growth. The isolation rate was higher in males 36/50 (72\%) compared to females $14 / 50(28 \%)$ in which its relationship with bedsores incidence was insignificant statistically p-value (0.778). The highest overall infection rate was in the age group 66 80 years, while the lowest was in the age group 80 - 95 years, which were statically insignificant with $\mathrm{p}$-value $(0.679)$. The most common infected sites was sacral region 36/50 (72\%) followed by neck $5 / 50(10 \%)$, buttock $4 / 50(8 \%)$, leg 3/50 (6\%) and heel 2/50 (4\%), which statically insignificant p-value (0.569) as indicated in Table (1).

The most common isolates in this study were Gram negative bacilli 41/53 (77.3\%) with predominant isolate Pseudomonas aeruginosa 15/41 (36.5\%) followed by other bacilli like Klebsiella spp 12/41 (29.2\%) 4/41 Escherichia coli (9.7\%), Citrobacter freundii 3/41 (7.3\%), Proteus spp 3/41 (7.3\%), Salmonella spp 2/41 (4.8\%) and Acinetobacter baumannii 2/41 (4.8\%). In the Gram positive bacteria the main organism identified was Staphylococcus aureus 12/53 (22.6\%) as shown in Table (2). The result showed insignificant relationship between isolated bacteria and underline disease and period of hospitalization p-value $(0.181),(0.488)$ respectively.

The antimicrobial susceptibility patterns of isolated bacteria from bedsores revealed that all isolated Staphylococcus aureus were resistant to Penicillin and Oxacillin $(100 \%)$ as shown in table (3). Meropenem is relatively effective formost isolated Pseudomonas aeruginosa and Gram negative bacilli except; Proteus spp, Salmonella spp, Acinetobacter baumannii and Klebsiella pneumoniae which were found to be $(100 \%)$ resistant as indicated in table (4). Pseudomonas aeruginosa was resistant to Co-trimoxazole 13/15 (86.7\%), Amoxicillin, Ciprofloxacin, and Ceftazidime $(80 \%)$, as shown in table (5). Out of 53 bacterial isolates introduced to multi-drug resistant organism criteria describes by clinical laboratory standards institute CLSI guidelines (resistant to three or more antimicrobial classes (Livesley et al., 2002). All isolated bacteria considered as (MDROs) organism except few strain of Pseudomonas aeruginosa and Citrobacter freundii 2/15 $(13.3 \%), 1 / 3(33.3 \%)$ respectively shown in table (6). 
Table.1 Socio-demographic and clinical characteristics of bedsores infected patients (December 2019 to February 2020)

\begin{tabular}{|c|c|c|c|}
\hline Characteristics & $\begin{array}{c}\text { Number }(\%) \text { of } \\
\text { tested }\end{array}$ & $\begin{array}{c}\text { Number }(\%) \text { of } \\
\text { culture positive }\end{array}$ & p-value \\
\hline Gender & & & \\
\hline Male & $43 / 57(75.4 \%)$ & $36(72 \%)$ & .778 \\
\hline Female & $14 / 57(24.5 \%)$ & $14(28 \%)$ & \\
\hline Total & $57(100 \%)$ & $50(100 \%)$ & \\
\hline Age in year & & & \\
\hline $\mathbf{2 0}-\mathbf{3 5}$ & $12(21 \%)$ & $9(18 \%)$ & \\
\hline $\mathbf{3 6}-\mathbf{5 0}$ & $10(17.6 \%)$ & $9(18 \%)$ & \\
\hline $\mathbf{5 1}-\mathbf{6 5}$ & $10(17.6 \%)$ & $9(18 \%)$ & \\
\hline $\mathbf{6 6}-\mathbf{8 0}$ & $21(36.8 \%)$ & $20(40 \%)$ & \\
\hline $\mathbf{8 1}-\mathbf{9 5}$ & $4(7 \%)$ & $3(6 \%)$ & \\
\hline Site of ulcer & & & \\
\hline Sacral & $38(66.7 \%)$ & $36(72 \%)$ & \\
\hline Neck & $7(12.2 \%)$ & $5(10 \%)$ & \\
\hline Buttock & $6(10.5 \%)$ & $4(8 \%)$ & \\
\hline Leg & $4(7 \%)$ & $3(6 \%)$ & \\
\hline Heel & $2(3.5 \%)$ & $2(4 \%)$ & \\
\hline Total & $57(100 \%)$ & $50(100 \%)$ & \\
\hline
\end{tabular}

Table.2 Distribution of positive bacterial isolates identified from bedsores swab specimens

\begin{tabular}{|c|c|c|}
\hline Type of isolates & Number of isolate & Percentage \\
\hline Gram positive isolates & & \\
\hline Staphylococcus aureus & 12 & $22.6 \%$ \\
\hline Gram negative isolates & & \\
\hline Pseudomonas aeruginosa & 15 & $28.3 \%$ \\
\hline Proteus vulgaris & 2 & $3.7 \%$ \\
\hline Klebsiella ozaenae & 4 & $7.5 \%$ \\
\hline Escherichia coli & 4 & $7.5 \%$ \\
\hline Proteus mirabilis & 1 & $1.8 \%$ \\
\hline Citrobacter freundii & 3 & $5.8 \%$ \\
\hline Klebsiella pneumoniae & 3 & $5.8 \%$ \\
\hline Acinetobacter baumannii & 2 & $3.7 \%$ \\
\hline Klebsiella oxytoca & 5 & $9.5 \%$ \\
\hline Salmonella spp & 2 & $3.7 \%$ \\
\hline Total & 53 & $100 \%$ \\
\hline
\end{tabular}


Table.3 Antimicrobial Susceptibility Pattern of Staphylococcus aureus

\begin{tabular}{|c|c|c|c|c|c|c|c|c|c|}
\hline $\begin{array}{c}\text { Staphylococcus } \\
\text { aureus }\end{array}$ & \multicolumn{10}{|c|}{ Antimicrobial agent } \\
\hline & COT & GEN & TE & CIP & AMX & ERY & PEN & VAN & OXA \\
\hline Sensitive & 4 & 3 & 5 & 3 & 4 & 2 & 0 & 3 & 0 \\
\hline Resistant & 8 & 9 & 7 & 9 & 8 & 10 & 12 & 9 & 12 \\
\hline
\end{tabular}

$\mathrm{PEN}=$ Penicillin ; COT $=$ Co-trimexazole $;$ GEN $=$ Gentamicin $; \mathrm{TE}=$ Tetracycline; ERY = Erythromycin OXA = Oxacillin; VAN = Vancomicin; AMX = Amoxicillin; CIP = Ciprofloxacin

Table.4 Antimicrobial Susceptibility Pattern of Enterobacteriacae Isolated from Bedsores (December 2019 to February 2020)

\begin{tabular}{|c|c|c|c|c|c|c|c|c|c|c|c|c|c|c|}
\hline Isolates & \multicolumn{10}{c|}{ Number of strains resistant to } \\
\hline & \multicolumn{1}{|c|}{ CIP } & \multicolumn{1}{|c|}{ COT } & AMX & TE & GEN & CAM & \multicolumn{2}{|c|}{ MEM } \\
\hline & S & R & S & R & S & R & S & R & S & R & S & R & S & R \\
\hline Proteus vulgaris & 1 & 1 & 0 & 2 & 1 & 1 & 0 & 2 & 1 & 1 & 0 & 2 & 0 & 2 \\
\hline Klebsiella ozaenae & 1 & 3 & 0 & 4 & 0 & 4 & 0 & 4 & 2 & 2 & 2 & 2 & 1 & 3 \\
\hline Escherichia coli & 1 & 3 & 0 & 4 & 0 & 4 & 0 & 4 & 3 & 1 & 1 & 3 & 4 & 0 \\
\hline Proteus mirabilis & 0 & 1 & 0 & 1 & 1 & 0 & 0 & 1 & 1 & 0 & 0 & 1 & 0 & 1 \\
\hline Citrobacter freundii & 2 & 1 & 1 & 2 & 1 & 2 & 2 & 1 & 1 & 2 & 1 & 2 & 1 & 2 \\
\hline Klebsiella pneumoniae & 0 & 3 & 1 & 2 & 1 & 2 & 0 & 3 & 2 & 1 & 0 & 3 & 0 & 3 \\
\hline Klebsiella oxytoca & 2 & 3 & 2 & 3 & 0 & 5 & 1 & 4 & 2 & 3 & 2 & 3 & 2 & 3 \\
\hline Salmonella spp & 1 & 1 & 0 & 2 & 0 & 2 & 0 & 2 & 1 & 1 & 1 & 1 & 0 & 2 \\
\hline
\end{tabular}

CAM = Chloramphenicol; COT = Co-trimexazole; GEN = Gentamicin; TE = Tetracycline; AMX= Amoxicillin CIP = Ciprofloxacin

Table.5 Antimicrobial Susceptibility Pattern of Pseudomonas aeruginosa and Acintobacter baumanii

\begin{tabular}{|c|c|c|c|c|c|c|c|c|c|c|c|c|c|c|}
\hline Isolates & \multicolumn{11}{c|}{ Number of strains resistant to } \\
\hline & \multicolumn{10}{c|}{ CIP } & \multicolumn{1}{c|}{ COT } & \multicolumn{2}{c|}{ MEM } & \multicolumn{2}{c|}{ DO } & \multicolumn{1}{c|}{ GEN } & \multicolumn{2}{|c|}{ AMX } & \multicolumn{2}{c|}{ CAZ } \\
\hline & S & R & S & R & S & R & S & R & S & R & S & R & S & R \\
\hline $\begin{array}{c}\text { Pseudomonas } \\
\text { aeruginosa }\end{array}$ & 3 & 12 & 2 & 13 & 6 & 9 & 5 & 10 & 6 & 9 & 3 & 12 & 3 & 12 \\
\hline $\begin{array}{c}\text { Acinetobacter } \\
\text { baumannii }\end{array}$ & 1 & 1 & 0 & 2 & 0 & 2 & 0 & 2 & 0 & 2 & 0 & 2 & 0 & 2 \\
\hline
\end{tabular}

CAM = Chloramphenicol; $\mathrm{COT}=$ Co-trimexazole; $\mathrm{GEN}=$ Gentamicin $; \mathrm{CAZ}=$ Ceftazidime; $\mathrm{AMX}=$ Amoxicillin CIP = Ciprofloxacin; DO = Doxycycline 
Table.6 Antimicrobial Susceptibility Pattern for MDR- Bedsore Isolates

\begin{tabular}{|c|c|c|c|}
\hline Isolated bacteria & Sensitive & Resistant (MDROS) & Total \\
\hline $\begin{array}{c}\text { Pseudomonas } \\
\text { aeruginosa }\end{array}$ & $2(13.3 \%)$ & $13(86.6 \%)$ & 15 \\
\hline Proteus vulgaris & 0 & $2(100 \%)$ & 2 \\
\hline Klebsiella ozaenae & 0 & $4(100 \%)$ & 4 \\
\hline Escherichia coli & 0 & $4(100 \%)$ & 3 \\
\hline Citrobacter freundii & $1(33.3 \%)$ & $2(66.9 \%)$ & 2 \\
\hline $\begin{array}{c}\text { Acinetobacter } \\
\text { baumannii }\end{array}$ & 0 & $2(100 \%)$ & 2 \\
\hline Salmonella spp & 0 & $2(100 \%)$ & 1 \\
\hline Proteus mirabilis & 0 & $1(100 \%)$ & 12 \\
\hline Staphylococcus aureus & 0 & $12(100 \%)$ & 3 \\
\hline Klebsiella pneumoniae & 0 & $3(100 \%)$ & 5 \\
\hline Klebsiella oxytoca & 0 & $5(100 \%)$ & \\
\hline
\end{tabular}

MDROS = Multi-Drugs Resistant Micro-organisms

Bedsores have important consequences both for patients and for the health care system. It can lead to severe or intolerable pain, are prone to infection and are associated with high mortality rates. They also inflict a considerable economic burden on the health care system (Reihani et al., 2007). The present study describes the distribution and antimicrobial susceptibility pattern of aerobic bacterial species isolated from bedsores infection. The rate of bacterial isolation was $36 / 50$ (72 \%), 4/50 (28\%) from male and female respectively, in which its relationship with bedsores incidence was statistically insignificant. This results is consistent with other studies done by (Reihani et al., 2007), (Gallagher et al., 2008) and (Mostafa Shokati Ahmadabad, 2015) in which there was no statistical association between genders and bedsores incidence rate. Moreover, the result showed that bedsores infection more common among age group 66-80 (40\%). Which agrees with the findings of earlier work carried out by (Abbott et al., 2002) who reported the bedsores were more common in men and in patients over 60 years of age. The present study reported that the frequency of bedsores with respect to the location on the body was high at the sacral $36 / 50(72 \%)$ followed by neck 5/50(10\%), buttock 4/50 (8\%), leg $3 / 50(6 \%)$ and heel $2 / 50(4 \%)$. The same finding was reported in several recent studies by (Reihani et al., 2007; Mostafa Shokati Ahmadabad, 2015) they showed that the most common sites were sacral regions (28.9\%), (54\%), (30\%) respectively. The present study revealed that gram-negative bacteria were the prominent pathogens consisting $77.3 \%$ of the isolates with high frequency of Pseudomonas aeruginosa 15/41 (36.5\%) followed by Klebsiella spp 12/41 (29.2\%) 4/41 Escherichia coli $(9.7 \%)$, Citrobacter freundii 3/41 (7.3\%), Proteus spp3/41 (7.3\%), Salmonella spp 2/41 (4.8\%) and Acinetobacter baumannii 2/41 (4.8\%). Similar to study by (Khanafari et al., 2013) who repeated that Pseudomonas aeruginosa (60\%), Escherichia coli $(35 \%)$ and Staphylococcus aureus (5\%) were dominant bacteria in all 20 bedsores samples. Also prospective study done by (Dolati et al., 2017) was reported that the frequently of identified bacteria detected by aerobic culturing from the bedsores of all studied patients showed that Pseudomonas species $18 / 49 \quad$ (36\%) Staphylococcus aureus 16/49 (32\%) and Escherichia coli 15/49 (30\%) were the most 
abundant microorganisms isolated. However, Proteus spp 4/49 (8\%) and Klebsiella spp 5/49 $(10 \%)$ were less frequency. In contrast study by Ghaly have documented that Staphylococcus epidermidis was the most prominent pathogen isolated from pressure sore $(31.4 \%)$ followed by Proteus vulgaris (28.6\%), Pseudomonas aeruginosa (22.8\%), Escherichia coli (8.6\%), Klebsiella pneumoniae $(5.8 \%)$ and Staphylococcus aureus (2.8\%) (Ghaly et al., 2010). The possible reason for variation in these studies could be attributed to differences in the populations investigated; diversity of bedsores sites, as well as timing of specimen collections. In the present study the majority of the isolates were obtained from patients already on antimicrobial treatment and this could have led to the low recovery of antimicrobial susceptible pathogens. According to achieved results from present study, it was found that $87.7 \%$ of patients hospitalized in ICU affected by bedsores (pressure ulcer). While in a study conducted in four European countries was found that the PU prevalence in ICU was $14 \%$ in Italy $4 \%$ in Denmark, 38\% in Netherlands and 49\% in Germany (Weststrate et al., 2001). A different studies reported that the incidence rate of PU was 16\% in Spain (Manzano et al., 2010), $15.5 \%$ in Turkey (Karayurt et al., 2016), $39.3 \%$ in Saudi Arabia (Tayyib et al., 2016), $13.6 \%$ in Brazil (Becker et al., 2017). In addition, a prevalence study in the Dutch found that the PU prevalence was $28.7 \%$. (Bours et al., 2001).The differences in the prevalence could be due to different infection control programs and general hygiene levels of the country. All isolates Staphylococcus aureus in present study were resistant to penicillin and Oxicillin. Furthermore, our study identified that Meropenem and Doxacillin was the most effective antibiotic against Pseudomonas aeruginosa. On the other hand, most Gram negative bacteria were highly resistance to Co- trimoxazole and
Amoxicillin. Additionally Ciprofloxacin, Cotrimoxazole and Gentamycinare the most antibiotics that were used for treating bedsores infection in Khartoum state hospitals. However the drugs were given immediately upon admission either combined or alternatively depending on the severity of infection, but not on the types of pathogen or its pattern of sensitivity and this could be the cause of the prevalence of Multi-drugs resistant bacteria (94.3\%) from the total isolates.

The present study findings indicate there are high prevalence of bedsores among patients admitted to intensive care unit in Khartoum state, with Pseudomonas aeruginosa as the most prevalent isolate bacterium in the bedsore patients, with $40 \%$ sensitivity to Meropenem, Gentamicin and $80 \%$ resistant to Amoxicillin, Ciprofloxacin and Ceftazidime. All Staphylococcus aureus isolates were resistant to Penicillin and Oxacillin (100\%). Additionally all isolated bacteria considered MDROs organism except few strain of Pseudomonas aeruginosa and Citrobacter freundii. The high isolation rate of aerobic bacteria from bedsores and increased drug resistance to the commonly used antibiotics warrants the need for immediate measures ensuring effective infection prevention and rational use of antimicrobial agents leading to minimize infection rate and emergence of drug resistance also alarm for physicians to change their treatment pattern depending on antimicrobial susceptibility results.

\section{References}

Abbott, C., Carrington, A., Ashe, H., Bath, S., Every, L., Griffiths, J., Hann, A., Hussein, A., Jackson, N. \& Johnson, K. 2002. The North-West Diabetes Foot Care Study: Incidence Of, And Risk Factors For, New Diabetic Foot Ulceration In A Community-Based 
Patient Cohort. Diabetic Medicine, 19, 377-384.

Agrawal, K. \& Chauhan, N. 2012. Pressure Ulcers: Back To The Basics. Indian Journal Of Plastic Surgery: Official Publication Of The Association of Plastic Surgeons Of India, 45, 244.

Becker, D., Tozo, T. C., Batista, S. S., Mattos, A. L., Silva, M. C. B., Rigon, S., Laynes, R. L., Salomão, E. C., Hubner, K. D. G., Sorbara, S. G. B. \& Duarte, P. A. D. 2017. Pressure Ulcers In Icu Patients: Incidence And Clinical And Epidemiological Features: A Multicenter Study In Southern Brazil. Intensive And Critical Care Nursing, 42, 55-61.

Bours, G., Laat, D. E., Halfens, R. \& Lubbers, M. 2001. Prevalence, Risk Factors And Prevention Of Pressure Ulcers In Dutch Intensive Care Units. Intensive Care Medicine, 27, 1599-1605.

Braga, I. A., Brito, C. S., Diogo Filho, A., Gontijo Filho, P. P. \& Ribas, R. M. 2017. Pressure Ulcer As A Reservoir Of Multiresistant Gram-Negative Bacilli: Risk Factors For Colonization And Development Of Bacteremia. Brazilian Journal of Infectious Diseases, 21, 171-175.

Burdette-Taylor, S. R. \& Kass, J. 2002. Heel Ulcers In Critical Care Units: A Major Pressure Problem. Critical Care Nursing Quarterly, 25, 41-53.

Chhugani, M., Jacob, S. M. \& James, M. M. 2017. Nursing Care: Making A Big Difference In Stage 3 Bed Sore. Int. J. Nurs. Midwif. Res, 4, 4.

Clsi, W. L. 2015. M02-A11: Performance Standards For Antimicrobial Disk Susceptibility Tests; Approved Standard. Clsi (Clinical And Laboratory Standards Institute), Vol32 (1).

Dolati, M., Javadi, A., Kariz, S. Z. \& Saki, B. G. 2017. Phenotypic And Molecular
Identification Of Bacteria Involved In Decubitus Ulcers. Journal Of Medical Bacteriology, 6, 45-55.

Gallagher, P., Barry, P., Hartigan, I., Mccluskey, P., O'connor, K. \& O'connor, M. 2008. Prevalence Of Pressure Ulcers In Three University Teaching Hospitals In Ireland. J Tissue Viability, 17, 103-9.

Ghaly, M., Shalaby, M., Shash, S., Baraka, D. \& Aly, R. 2010. Control Of Bacterial Contamination Of Bed Sores By Using Some Natural Extracts. Journal of Applied Sciences Research, 70-80.

Ghodela, N. \& Dudhamal, T. 2018. Management Of Bed Sores With Thumari Gel [Securinega Leucopyrus (Willd.) Muell.]-An ExtraPharmacopeal Drug-A Case Study. International Journal Of Ayush Case Reports, 2, 20-25.

Karayurt, O., Akyol, O., Kilicaslan, N., Akgun, N., Sargin, U., Kondakci, M., Ekinci, H. \& Sari, N. 2016. The Incidence Of Pressure Ulcer In Patients On Mechanical Ventilation Andeffects Of Selected Risk Factors On Pressure Ulcer Development. Turk J Med Sci, 46, 1314-1322.

Khanafari, A., Yaghoub Nezhad Zangeneh, G. \& Sharifnia, F. 2013. Combined Application Of Microbial Cellulose And Papaver Macrostomum Extract On Bedsore Microorganisms. Jundishapur Journal Of Microbiology.

Livesley, N. J. \& Chow, A. W. 2002. Infected Pressure Ulcers In Elderly Individuals. Clinical Infectious Diseases, 13901396.

Magiorakos, A.-P., Srinivasan, A., Carey, R., Carmeli, Y., Falagas, M., Giske, C., Harbarth, S., Hindler, J., Kahlmeter, G. \& Olsson-Liljequist, B. 2012. Multidrug-Resistant, Extensively Drug-Resistant And Pandrug-Resistant Bacteria: An International Expert 
Proposal For Interim Standard Definitions For Acquired Resistance. Clinical Microbiology And Infection, 18, 268-281.

Manzano, F., Navarro, M. J., Roldán, D., Moral, M. A., Leyva, I., Guerrero, C., Sanchez, M. A., Colmenero, M. \& Fernández-Mondejar, E. 2010. Pressure Ulcer Incidence And Risk Factors In Ventilated Intensive Care Patients. Journal Of Critical Care, 25, 469-476.

Mostafa Shokati Ahmadabad1, H. R., Mahmoud Alipoor Heydari3, Mohammad Bokharaei1, Masoud Amiri4 2015. Incidence Of Pressure Ulcer In Patients Who Were Admitted To Open Heart Cardiac Surgery Intensive Care Unit.

Reihani, H. \& Haghiri, A. 2007. Determination Of Bed Sore Risk Factors In Craniospinal Trauma Patients In Intensive Care Units.
Journal Of Arak University Of Medical Sciences, 10, 39-46.

Repić, G. \& Ivanović, S. 2014. Pressure Ulcers And Their Impact On Quality Of Life. Acta Medica Medianae, 53, 75-80.

Sarin, M., Vadivelan, M. \& Bammigatti, C. 2013. Antimicrobial Therapy In The Intensive Care Unit.

Tayyib, N., Coyer, F. \& Lewis, P. 2016. Saudi Arabian Adult Intensive Care Unit Pressure Ulcer Incidence And Risk Factors: A Prospective Cohort Study. Int Wound J, 13, 912-9.

Weststrate, J. \& Heule, F. 2001. Prevalence Of Pressure Ulcers, Risk Factors And Use Of Pressure-Relieving Mattresses In Icu Patients. Connect: The World Of Critical Care Nursing, 1, 77-82.

Yarkony, G. M. 1994. Pressure Ulcers: A Review. Archives Of Physical Medicine And Rehabilitation, 75, 908917.

\section{How to cite this article:}

Alzpair I. Ibrahim, Alsafi B. Mukhtar, Mahmoud H. Ahmed, Suliman M. Yahia and Alamin M. Ibrahim. 2021. Prevalence and Antimicrobial Susceptibility Pattern of Aerobic Bacteria Isolated from Patients with Bedsores Admitted to Intensive Care Units in Khartoum State. Int.J.Curr.Microbiol.App.Sci. 10(05): 759-767. doi: https://doi.org/10.20546/ijcmas.2021.1005.086 